\title{
Resistance to Bean common mosaic necrosis virus Conferred by the $b c-1$ Gene Affects Systemic Spread of the Virus in Common Bean
}

\author{
Xue Feng, Pablo Guzmán, James R. Myers, and Alexander V. Karasev
}

First and fourth authors: Department of PSES, University of Idaho, Moscow; second author: California Crop Improvement Association, Davis; third author: Department of Horticulture, Oregon State University, Corvallis; and fourth author: Bioinformatics and Computational Biology Program, University of Idaho, Moscow.

Accepted for publication 24 March 2017.

\begin{abstract}
Bean common mosaic necrosis virus (BCMNV) isolates belong to two pathogroups (PG), PG-III and PG-VI, which are distinguished in common bean due to the inability of the PG-III isolates of BCMNV to overcome the two recessive resistance alleles $b c-1$ and $b c-1^{2}$. The biological and molecular basis of this distinction between PG-III and PG-VI isolates of $\mathrm{BCMNV}$ is not known. Here, three isolates of BCMNV were typed biologically on a set of 12 bean differentials and molecularly through wholegenome sequencing. Two isolates (1755b and TN1a) were assigned to PG-VI and one isolate (NL8-CA) was assigned to PG-III. Isolate NL8-CA (PG-III) induced only local necrosis on inoculated leaves in 'Top Crop' and 'Jubila' bean harboring the $I$ gene and the $b c-1$ allele, whereas isolates TN1, TN1a, and 1755b (all PG-VI) induced rapid whole-plant necrosis (WPN) in Top Crop 7 to 14 days postinoculation, and severe systemic necrosis but not WPN in Jubila 3 to 5 weeks postinoculation. In 'Redland Greenleaf C'

expressing $b c-1$ and 'Redland Greenleaf B' expressing $b c-1^{2}$ alleles, isolate NL8-CA was able to systemically infect only a small proportion of upper uninoculated leaves (less than 13 and 3\%, respectively). The whole genomes of isolates 1755b, TN1a, and NL8-CA were sequenced and sequence analysis revealed that, despite the overall high nucleotide sequence identity between PG-III and PG-VI isolates (approximately 96\%), two areas of the BCMNV genome in the P1/HC-Pro and HC-Pro/ $\mathrm{P} 3$ cistrons appeared to be more divergent between these two pathotypes of BCMNV. The data suggest that the phenotypic differences among PGIII and PG-VI isolates of BCMNV in common bean cultivars from host resistance groups 2,3 , and 9 carrying $b c-1$ alleles were related to the impaired systemic movement of the PG-III isolates to the upper, uninoculated leaves, and also suggest a role of the recessive $b c-1$ gene in interfering with systemic spread of BCMNV.
\end{abstract}

Bean common mosaic necrosis virus (BCMNV) is a potyvirus, closely related to Bean common mosaic virus (BCMV) (Adams et al. 2012). BCMNV has a single-stranded, positive-sense RNA genome of $9.6 \mathrm{~kb}$, excluding poly(A), that encodes a 3,071-aminoacid (aa) polyprotein later cleaved by virus-encoded proteases into 10 mature proteins (Fang et al. 1995; Larsen et al. 2011). Both BCMNV and BCMV are economically important pathogens of common bean (Phaseolus vulgaris L.), primarily transmitted through seed and spread in the field by aphids in a nonpersistent manner (Flores-Estévez et al. 2003; Morales and Bos 1988; Singh and Schwartz 2010; Worrall et al. 2015). The resistance to BCMNV and BCMV isolates in common bean is conferred by five resistance genes: one dominant $I$ gene and four recessive genes $(b c-u, b c-1 / b c$ $1^{2}, b c-2 / b c-2^{2}$, and $b c-3 ; b c-1$ and $b c-2$ have two alleles each) (Drijfhout 1978). BCMNV and BCMV isolates are classified into eight pathogroups (PG), numbered from I to VIII, which are based on patterns of interactions with these five resistance genes (Drijfhout and Morales 2005; Feng et al. 2015). In turn, common bean cultivars were grouped into host groups (HG) numbered 1 to 11 carrying different combinations of the resistance alleles (Drijfhout and Morales 2005). BCMNV isolates were found associated only with PG-III and PG-VI, whereas isolates of BCMV could be found in all eight PG (Drijfhout 1978; Feng et al. 2015; Larsen et al. 2005, 2011). Both viruses are serologically distinct, with BCMNV displaying A-serotype and BCMV displaying B-serotype, and can be easily differentiated using

Corresponding author: A. V. Karasev; E-mail address: akarasev@uidaho.edu

*The $\boldsymbol{e}$-Xtra logo stands for "electronic extra" and indicates that one supplementary figure and one supplementary table are published online.

(c) 2017 The American Phytopathological Society monoclonal or polyclonal antisera (Feng et al. 2014b; Mink and Silbernagel 1992; Strausbaugh et al. 2003a; Vetten et al. 1992).

The dominant $I$ gene confers immunity against all strains of BCMV in common bean below $30^{\circ} \mathrm{C}$ (Ali 1950; Collmer et al. 2000). Above $30^{\circ} \mathrm{C}, \mathrm{BCMV}$ infection in plants with the dominant $I$ gene usually experience whole plant necrosis (WPN, also referred to as "black root"). BCMNV can be easily distinguished from BCMV biologically due to its ability to induce rapid, temperatureinsensitive WPN in bean cultivars carrying an unprotected $I$ gene (Drijfhout 1978). The term "unprotected I gene" refers to the genetic condition in which bean plants with the dominant $I$ gene are not protected from WPN in the absence of one or more of the $b c-1, b c-2$, or $b c-3$ recessive alleles. Since the $I$ gene was widely introduced into commercial common bean cultivars to protect them against BCMV (Singh and Schwartz 2010), BCMNV became a serious threat affecting bean production. Nearly all contemporary snap bean cultivars have an unprotected $I$ gene and, within dry bean, most cultivars in the navy, black, and kidney market classes have a similar form of resistance. Additional recessive genes can "protect" a cultivar from this BCMNV-induced WPN, although various degrees of local and systemic necrotic reaction can be observed in some of those protected cultivars following BCMV or BCMNV infection (Drijfhout 1978; Drijfhout and Morales 2005; Feng et al. 2014a; Larsen et al. 2005).

Information on biological or phenotypic diversity of BCMNV is limited, with only two pathotypes, PG-III (represented by isolate NL8) and PG-VI (isolates TN1, NL3, and NL5), identified among BCMNV isolates studied (Drijfhout 1978; Drijfhout and Morales 2005; Larsen et al. 2005, 2011). BCMNV isolates were also found to exhibit very limited sequence diversity, which ranged between 96 to $99 \%$ for the whole genomes of NL3, NL5, NL8, TN1, and TM70 isolates (Larsen et al. 2011; Maina et al. 2016). Although a natural recombinant of BCMNV, isolate NL3K, was previously described 
featuring an NL3 genome with a small, 0.4-kb insert of a BCMVRU1 sequence and increased virulence on some HG of common bean, this NL3K isolate was also assigned to PG-VI (Larsen et al. 2005; Strausbaugh et al. 2003a). Consequently, phenotypic differences between different BCMNV isolates-in particular, the distinction between PG-III and PG-VI types-could not be mapped to any specific region of the virus genome, and no BCMNV genome determinant was implicated in interactions with $b c-1$ and $b c-1^{2}$ alleles in common bean (Larsen et al. 2011).

Prior to 1992, BCMNV was considered a strain of BCMV and, in biological studies, was frequently lumped with the latter (Drijfhout 1978; Mink and Silbernagel 1992; Vetten et al. 1992). Hence, even with the relatively limited biological diversity of BCMNV, there is a general shortage of information on phenotypes of BCMNV isolates in common bean differentials correlated to the virus whole-genome sequences. Currently, only a limited number of complete BCMNV genome sequences is available in the GenBank database, and most of them belong to PG-VI (Fang et al. 1995; Larsen et al. 2005, 2011), with just a single NL8 sequence representing PG-III (Larsen et al. 2011). On the other hand, there are a few additional BCMNV sequences deposited in the GenBank database with no described phenotype in common bean. To fill in this knowledge gap in the absence of a manipulatable BCMNV infectious clone, and identify the virus genetic determinants involved in expression of phenotypes by BCMNV, including interactions with $b c-1$ and $b c-1^{2}$ alleles, preliminary or tentative mapping of these genetic determinants can be accomplished through comparative genomics, analyzing multiple, phenotypically different whole-genome sequences from different PG.

Here, we present the complete biological and molecular characterization of three field isolates of BCMNV collected in Oregon and California. Three distinct phenotypes were studied for BCMNV isolates in common bean: the ability to cause WPN in the cultivar 'Top Crop', the induction of systemic necrosis in the cultivar 'Jubila', and the ability to overcome $b c-1$ and $b c-1^{2}$ resistance alleles; or, in other words, the ability to systemically spread in common bean cultivars carrying these $b c-1$ and $b c-1^{2}$ alleles. Comparison of the biological and molecular properties of these three field isolates with other known BCMNV whole-genome sequences available in the GenBank database suggested that the virus genetic determinants responsible for all three phenotypes and, in particular, for interactions with $b c-1$ and $b c-1^{2}$ resistance alleles in common bean, may reside in the P1, HC-Pro, and P3 cistrons. Replication of all studied BCMNV isolates in inoculated leaves of bean differentials expressing $b c-1$ and $b c-1^{2}$ alleles, and impaired ability of NL8-CA to move systemically in these same cultivars, suggested that resistance gene $b c-1$ specifically affects long-distance movement of BCMNV isolates from PG-III in common bean.

\section{MATERIALS AND METHODS}

Virus sources and maintenance. The reference BCMNV isolate TN1 used in this work originated from the United States Department of Agriculture-Agricultural Research Service (USDAARS) Prosser, WA collection, and was described previously (Feng et al. 2014a,b; Larsen et al. 2011). BCMNV isolate NL8-CA was collected in 2015 near Davis, CA, as a field sample from an heirloom common bean 'Zuni Gold' displaying mosaic and stunting. The TN1a isolate of BCMNV was found in a sample of common bean exhibiting mosaic found in Corvallis, OR, in 2015. BCMNV isolate 1755 b was initially identified in field sample $91-1755$ collected in Willamette Valley, OR, in 2013 (Feng et al. 2015); this original sample contained a mixed infection comprising a 1755a isolate of BCMV and a $1755 \mathrm{~b}$ isolate of BCMNV. The $1755 \mathrm{~b}$ isolate of BCMNV was biologically separated from BCMV by passaging it through common bean 'Redlands Greenleaf B', nonpermissive for the PG-VIII isolate 1755a of BCMV (Feng et al. 2015). All virus isolates were propagated in 'Dubbele Witte' bean using mechanical inoculation and then maintained under greenhouse conditions.

Biological and serological characterization. The biological characterization of three field isolates of BCMNV on a set of 11 bean differentials (Drijfhout 1978) was performed as described previously for BCMV typing (Feng et al. 2014a,b), except that one additional cultivar, Top Crop, was added to the set. Top Crop was received from the USDA-ARS Germplasm Collection in Pullman, WA, where it is maintained as part of the BCMV differential set. One reference strain of BCMNV, TN1 (PG-VI), was included in this analysis as control. All 12 bean differential lines carrying different resistance gene combinations (Table 1) were inoculated with each isolate (three plants per cultivar per isolate), and plants were placed in the climate-controlled growth room with standard summertime growth conditions (16-h day photoperiod and day and night temperatures of 25 and $16^{\circ} \mathrm{C}$, respectively). The typing experiments were repeated three times for each cultivar-isolate combination. Symptoms were recorded at weekly intervals for 5 to 8 weeks postinoculation (wpi). For Top Crop and Jubila, inoculated leaves were collected and tested at 10 to 15 days postinoculation (dpi), and

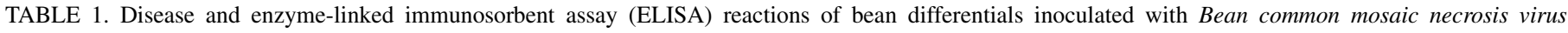
(BCMNV) isolates ${ }^{\mathrm{a}}$

\begin{tabular}{|c|c|c|c|c|c|c|}
\hline \multirow[b]{2}{*}{$\mathrm{HG}^{\mathrm{b}}$} & \multirow[b]{2}{*}{ Resistance alleles } & \multirow[b]{2}{*}{ Cultivar } & \multicolumn{4}{|c|}{ BCMNV isolate (pathogroup) } \\
\hline & & & NL8-CA (PG-III) & TN1a (PG-VI) & 1755b (PG-VI) & TN1 (PG-VI) ${ }^{\mathrm{c}}$ \\
\hline 0 & None & Dubbele Witte & $+/+$ & $+/+$ & $+/+$ & $+/+$ \\
\hline 1 & $i, b c-u$ & 'Stringless Green Refugee' & $+/+$ & $+/+$ & $+/+$ & $+/+$ \\
\hline 2 & $i, b c-u, b c-1$ & Redlands Greenleaf C & $-1-$ & $+/+$ & $+/+$ & $+/+$ \\
\hline 3 & $i, b c-u, b c-1^{2}$ & Redlands Greenleaf B & $-1-$ & $+/+$ & $+/+$ & $+/+$ \\
\hline 4 & $i, b c-u, b c-2$ & 'Sanilac' & $+/+$ & $+/+$ & $+/+$ & $+/+$ \\
\hline 6 & $i, b c-u, b c-1^{2}, b c-2^{2}$ & 'UI35’ & $-1-$ & $-1-$ & $-1-$ & $-1-$ \\
\hline 7 & $i, b c-u, b c-2, b c-3$ & 'IVT7214' & $-1-$ & $-1-$ & $-1-$ & $-1-$ \\
\hline 9 & $I, b c-1$ & Top Crop & + nll/- & + nll, WPN & + nll, WPN & + nll, WPN \\
\hline 9 & $I, b c-1$ & Jubila & $\pm \mathrm{n} / \pm$ & $+n / \pm$ & $+n / \pm$ & $+n / \pm$ \\
\hline 10 & $I, b c-1^{2}$ & 'Amanda' & $-1-$ & $-1-$ & $-1-$ & $-1-$ \\
\hline 11 & $I, b c-u, b c-1^{2}, b c-2^{2}$ & 'IVT7233' & $-1-$ & $-1-$ & $-1-$ & $-1-$ \\
\hline 12 & $I, b c-u, b c-2^{2}$ & ‘US1006’ & $-1-$ & $-1-$ & $-1-$ & $-1-$ \\
\hline
\end{tabular}

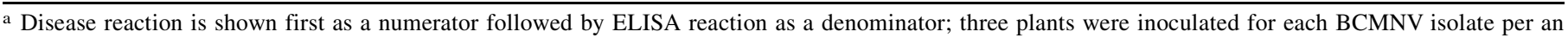
experiment. Numerator: $+=$ symptoms on inoculated bean; $-=$ no symptoms on inoculated bean; + nll $=$ necrotic local lesions on inoculated leaves; \pm n $=$ limited systemic vein necrosis on some upper, uninoculated leaves; $+n=$ systemic necrosis; and WPN = whole-plant necrosis and death within 7 to 14 days postinoculation. Denominator: + designates ELISA signal (absorbance at $405 \mathrm{~nm}$ ) in upper, uninoculated leaves exceeding healthy control threefold or more; \pm designates ELISA signal in necrotic areas of upper, uninoculated leaves exceeding healthy control threefold or more; and - designates ELISA signal in an infected plant equal to that of a healthy control.

b Host resistance group.

c Control. 
symptomatic (local necrotic lesions) and asymptomatic areas were cut and tested separately; upper uninoculated leaves were processed using the same method at 3 and 5 wpi. For the remaining cultivars, inoculated leaves were also collected and tested at 10 to $15 \mathrm{dpi}$; two to three symptomatic or asymptomatic uninoculated foliar samples were randomly collected for enzyme-linked immunosorbent assay (ELISA) testing at 4 to 5 wpi. For 'Redlands Greenleaf C' and Redlands Greenleaf B inoculated with NL8-CA, additional tests were conducted: inoculated leaves were collected and tested at 2 wpi, all uninoculated leaves were collected at 5 wpi, and each individual leaf was tested separately by ELISA. To test for the virus presence in leaf tissue, 0.5 -g pieces were cut from the leaves, ground in meshed extraction bags (Bioreba AG, Reinach, Switzerland) using the ELISA extraction buffer, and 200- $\mu$ l aliquots were loaded onto precoated ELISA plates as described (Feng et al. 2014b). Triple-antibody sandwich (TAS)-ELISA tests using BCMNVspecific polyclonal antibodies from the laboratory collection were performed as described previously (Feng et al. 2014b).

Cloning strategy, sequencing, and sequence analysis. The whole-genome cloning strategy, sequencing, and sequence analysis for BCMNV isolates 1755b, TN1a, and NL8-CA were conducted as described previously (Feng et al. 2014b). The whole genomes were amplified by reverse-transcription polymerase chain reaction (PCR) using four pairs of primers designed based on the aligned BCMNV sequences available in the GenBank database (Supplementary Table S1); the overlapping PCR products were cloned into the AT-vector T-Easy (Promega Corp., Madison, WI) and submitted for sequencing to GENEWIZ (South Plainfield, NJ), as described (Feng et al. 2014b). The 5'-terminal sequences for all three isolates were amplified using the rapid amplification of cDNA ends kit (Roche, Indianapolis, IN), and subsequently cloned and sequenced the same way as the rest of the genome. The complete viral genomes assembled using SeqMan (DNASTAR, Madison, WI) had been deposited in the GenBank database under the accession numbers KY659304 (NL8-CA), KY659306 (TN1a), and KY659305 (1755b). All sequences were initially analyzed using the BLASTn 2.2.17 (Altschul et al. 1997) tool available at the National Center for Biotechnology Information (NCBI). Open reading frames (ORF) were identified using the ORF Finder program available at the NCBI. Complete sequences of BCMV isolates were aligned using ClustralX (ver. 2.0; Conway Institute, University College Dublin, Dublin). Further analysis was conducted with the Recombination Detection Program v.4.16 (RDP4) (Martin et al. 2005).

\section{RESULTS}

Phenotypes of BCMNV isolates in common bean cultivars harboring or lacking the $\boldsymbol{I}$ gene. BCMNV isolates NL8-CA, TN1a, and 1755b induced typical mosaic and leaf deformations in susceptible common bean cultivars that lacked the I gene (Table 1), leading to leaf distortion, mosaic, blistering, and growth retardation. However, one isolate (NL8-CA) was unable to systemically infect Redlands Greenleaf B (HG-2) and Redlands Greenleaf $\mathrm{C}$ (HG-3) and, hence, was typed as belonging to PG III (Table 1), whereas the other two (TN1a and 1755b) infected Redlands Greenleaf B and Redlands Greenleaf C systemically, and were typed as belonging to PG VI (Table 1). The two latter isolates (TN1a and $1755 \mathrm{~b}$ ) had a pathogenicity profile identical to the control BCMNV isolate TN1 belonging to PG-VI.

Phenotypes of the three isolates in I-gene-bearing bean differentials differed only in Top Crop and Jubila (both HG-9). The three tested isolates (NL8-CA, TN1a, and 1755b) induced local necrotic lesions on primary inoculated leaves of Top Crop (Fig. 1). In all three cases, these lesions appeared at approximately 5 dpi and quickly expanded, reaching leaf veins and exhibiting extensive vein necrotic reaction by 10 dpi (Fig. 1A). By 10 dpi, two of the three BCMNV isolates tested (TN1a and 1755b) started to induce WPN (Fig. 1A), and plant death was observed in Top Crop by 16 dpi
(Fig. 1B), similar to the control isolate TN1 (Fig. 1B; Table 1). The WPN syndrome started from the growing point of the plant, spreading downward along the stem, and was similar to a typical black root reaction characteristic of common bean plants carrying an unprotected $I$ gene and infected with BCMNV (Drijfhout 1978). This rapid plant death was very quick for the three PG-VI isolates TN1, TN1a, and 1755b, taking place at 7 to $16 \mathrm{dpi}$; whereas, for the NL8-CA isolate, no systemic necrosis or WPN was observed for the entire period of observation, up to 6 to 8 wpi. No BCMNV spread was detected by ELISA testing in upper leaves, outside of the inoculated primary leaves for the NL8-CA isolate in Top Crop (Table 2), and the plants stayed visibly healthy, producing normal pods.

In Jubila, BCMNV isolate NL8-CA induced clearly visible local lesions on primary inoculated leaves, developing within 5 to $7 \mathrm{dpi}$ (Fig. 2). Local lesions on primary leaves inoculated with TN1a, $1755 \mathrm{~b}$, and the control isolate TN1 were less prominent than in the case of NL8-CA, and became clearly visible only after $10 \mathrm{dpi}$ (Fig. 3). Systemic symptoms in Jubila having the same genetic background as Top Crop ( $I$ and $b c-1)$ were less severe for all four tested isolates, and were exhibited as various degrees of systemic necrotic reaction (Table 1; Fig. 4). However, this systemic necrosis was different from WPN or black root reaction, in that it affected only leaves, leaving stem and petiole tissues relatively unaffected (Fig. $4)$, and did not result in the death of the infected plants during the entire duration of the experiment (6 to 8 weeks). There was a clear difference in necrotic symptoms caused by the NL8-CA isolate in Jubila versus isolates TN1, TN1a, and 1755b. NL8-CA induced only limited, spreading vein necrosis on some upper, uninoculated leaves, with most of the leaves exhibiting no necrosis (Table 2). The NL8-CA isolate, thus, induced very mild systemic reaction in inoculated Jubila plants, which produced normal pods and exhibited no growth retardation (Fig. 4A). The three other BCMNV isolates (TN1, TN1a, and 1755b) induced severe systemic necrosis which affected all leaves of the infected Jubila plants and led to severe growth retardation, stunting, and to reduction of the pod size (Fig. 4B to D).

Serological characterization of BCMNV isolates and assessment of the virus cell-to-cell and systemic movement in HG-9 common bean differentials. All three BCMNV isolates (NL8-CA, TN1a, and 1755b) exhibited A-serotype and reacted with anti-TN1-detecting antibody only in the TAS-ELISA (data not shown). The TAS-ELISA detection method confirmed the presence of the virus in upper uninoculated leaves of those inoculated bean differentials expressing mosaic and leaf deformation symptoms, and helped to assign NL8-CA to PG-III and TN1a and 1755b to PGVI (Table 1). Specifically, isolate NL8-CA did not induce visible symptoms in upper uninoculated leaves of bean differentials from HG-2 and HG-3 (Table 1), in contrast to isolates TN1, TN1a, and $1755 \mathrm{~b}$, which expressed typical virus symptoms in upper uninoculated leaves of the same differentials from HG-2 and HG-3. Nevertheless, the PG-III isolate NL8-CA replicated in inoculated leaves of Redlands Greenleaf C (HG-2) and Redlands Greenleaf B (HG-3), as determined by ELISA, as the three PG-VI isolates (Fig. 5), despite being unable to systemically infect either of these cultivars (Table 1). This suggested a normal, unimpaired cell-to-cell movement of the virus in the inoculated leaf of HG-2 and HG-3 bean cultivars for all four isolates but, at the same time, indicated the lack of normal long-distance spread in the same HG-2 and HG-3 bean cultivars for the isolate NL8-CA.

Plants of Top Crop (HG-9) inoculated with isolates TN1, TN1a, and $1755 \mathrm{~b}$ succumbed to the WPN within 7 to 14 dpi (Fig. 1), which was too rapid to use ELISA to measure systemic spread of the virus. In contrast, Top Crop inoculated with isolate NL8-CA exhibited less severe symptoms, which allowed testing for the virus presence in upper uninoculated leaves using ELISA (Table 2). All four isolates, including NL8-CA, were easily detectable in primary, inoculated leaves of Top Crop displaying necrotic lesions at 10 dpi but NL8-CA 
infection could not be observed or detected by ELISA in the upper uninoculated leaves for the duration of the experiment ( 6 to 8 weeks).

A much slower systemic necrotic reaction to BCMNV in Jubila (HG-9) allowed us to examine the virus presence in leaves exhibiting the necrotic reaction for all isolates. All four isolates of BCMNV tested were detected in primary inoculated leaves using the ELISA methodology within 10 dpi (Table 2). This suggested a normal, unimpaired cell-to-cell movement of the virus in the inoculated leaf of Jubila for all four isolates, including NL8-CA. In contrast to the inoculated leaves, NL8-CA was not detected in the upper uninoculated leaves of Jubila for up to 3 wpi (Table 2), which was consistent with the lack of the necrotic symptoms in these uninoculated leaves. Between 5 and 8 wpi, only three of six infected plants exhibited very limited vein necrotic patches on one to two leaves per plant (Table 2). NL8-CA was detected by ELISA in those few necrotic patches. The three other isolates (TN1, TN1a, and $1755 \mathrm{~b}$ ) were found in the upper, uninoculated leaves of Jubila in and around necrotic patches visible after 3 wpi (Table 2) but not in nonsymptomatic leaf tissue outside of these necrotic patches (not shown). This observation suggested a normal systemic spread of TN1, TN1a, and 1755b in Jubila but an impaired or inefficient systemic movement in the case of the NL8-CA isolate.

Long-distance movement of NL8-CA in bean cultivars from HG-2 and HG-3 is also impaired or inefficient. Because a small number of leaves in Jubila plants (HG-9) became systemically infected with NL8-CA after 5 wpi, visible as expressing limited vein necrosis and confirmed as BCMNVpositive in ELISA (Fig. 4A; Table 2), we decided to look more closely at NL8-CA infection in plants from HG-2 and HG-3 carrying alleles of the same $b c-1$ resistance gene present in HG-9 but without the $I$ gene. After inoculation of plants of Redlands Greenleaf C and Redlands Greenleaf B with NL8-CA, samples were taken from each of the inoculated leaves at $2 \mathrm{wpi}$, and later from each of the upper, uninoculated leaves at $5 \mathrm{wpi}$, and the BCMNV presence was assessed by ELISA (Table 3). Virus was easily detected in all inoculated leaves, indicating unimpaired cellto-cell movement of NL8-CA in both HG-2 and HG-3 cultivars. At 5 wpi, none of the upper, uninoculated leaves of Redlands Greenleaf

A

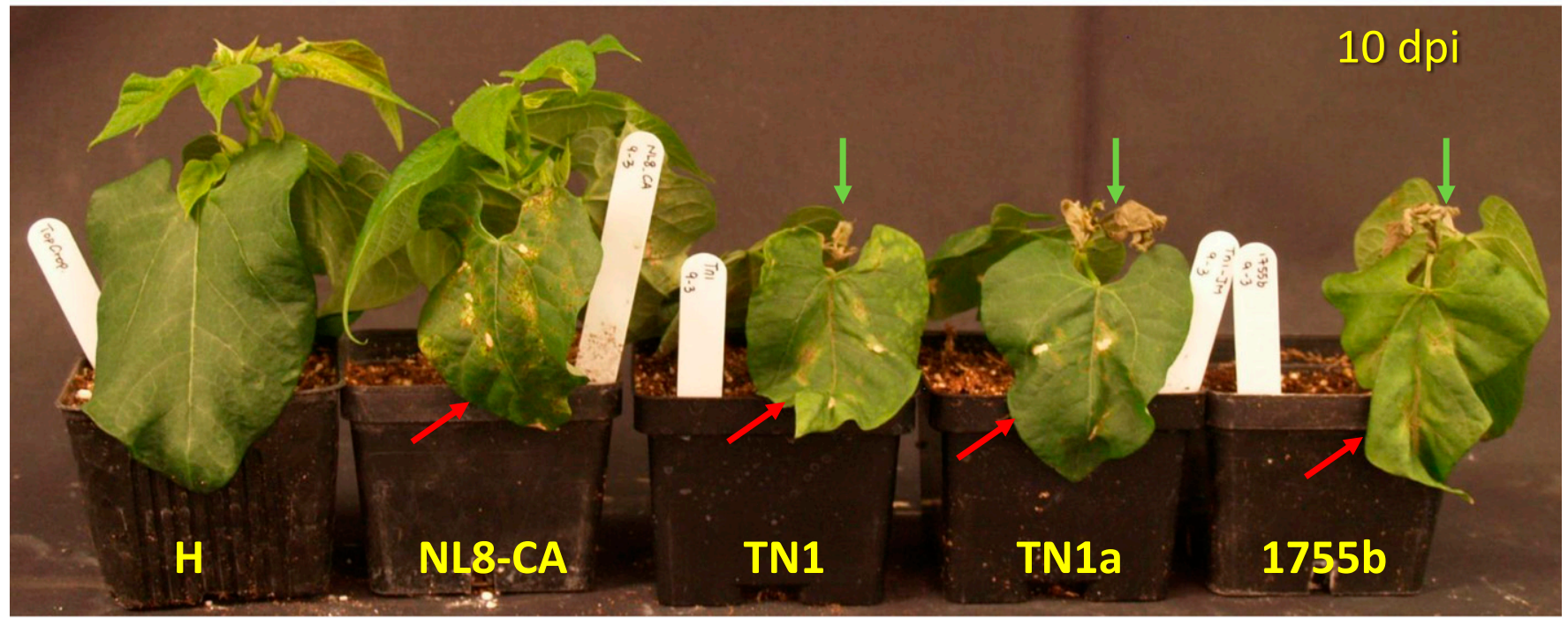

B

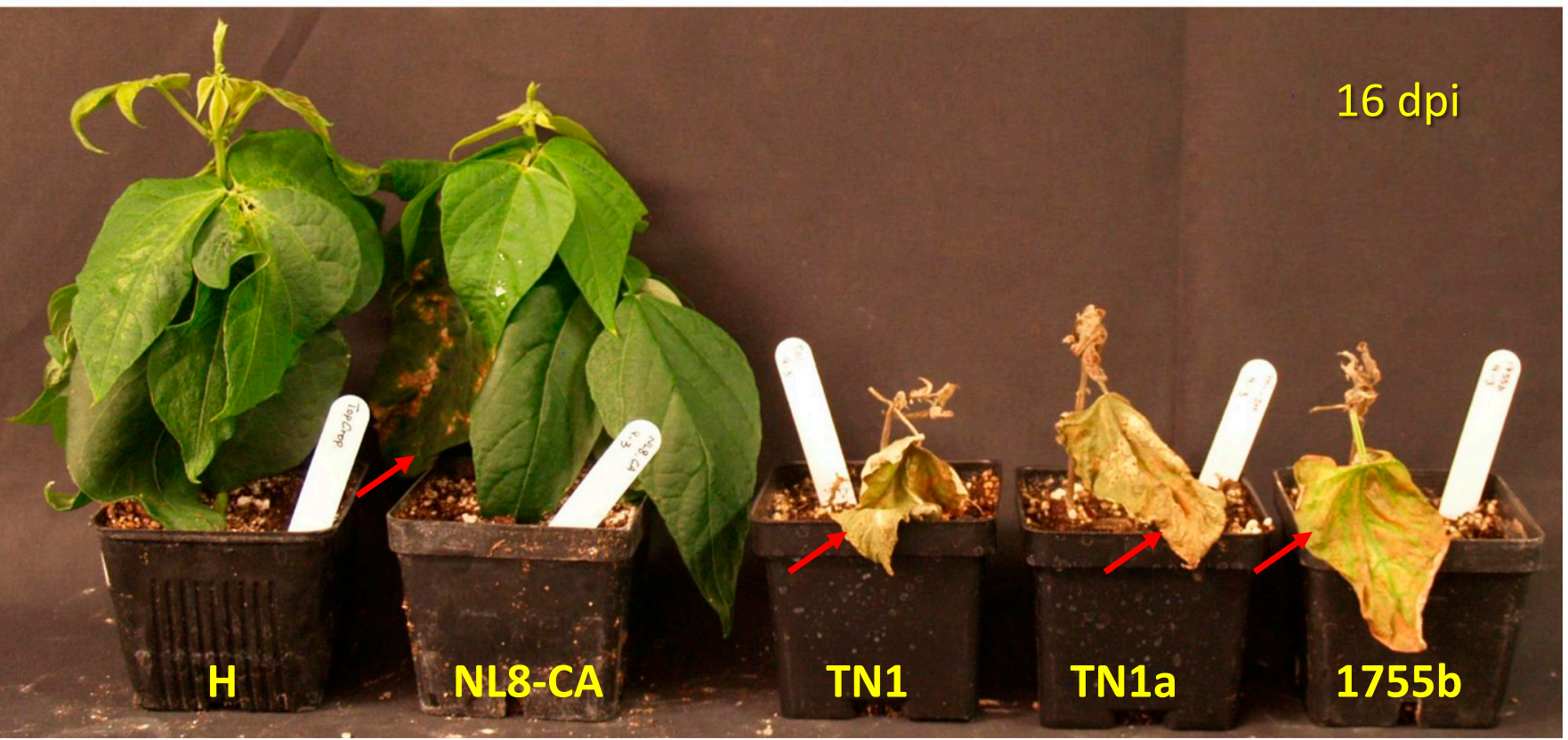

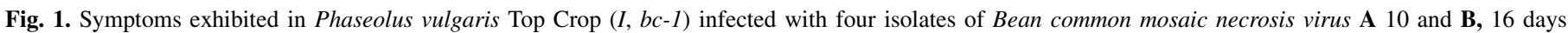

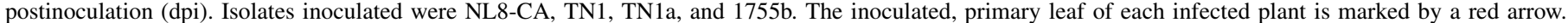
Green arrows mark necrotized growth points for isolates TN1, TN1a, and 1755b, indicating black root reaction in progress, and H marks a healthy plant. 
C and Redlands Greenleaf B expressed visible symptoms of BCMNV infection; however, a small proportion of these uninoculated leaves were found to be BCMNV positive (Table 3 ). This proportion varied from 8 to $13 \%$ for Redlands Greenleaf C (HG-2, $b c-u$ and $b c-1)$ to 2 to $3 \%$ for Redlands Greenleaf B (HG-3, $b c-u$ and $b c-1^{2}$ ). The ELISA signal in each of these systemically infected leaves was found to be high and unequivocally pointed at BCMNV infection, despite the absence of visible symptoms. Hence, the long-distance spread of NL8-CA was apparently inefficient in the presence of $b c-1$ and $b c-1^{2}$ alleles carried by HG-2 and HG-3 cultivars, respectively. This was consistent with observations of the NL8-CA infection in HG-9 cultivars, where systemic spread of this isolate was also impaired in the presence of $b c-1$ (Fig. 4A; Table 2).

Whole-genome sequencing and sequence analysis. The whole genomes of BCMNV isolates NL8-CA, TN1a, and 1755b were cloned and sequenced, using the approach described previously (Feng et al. 2014b). Upon sequence assembly, NL8-CA was found to be 9,627 nucleotides (nt) long, excluding the poly (A). Based on conceptual translation, the BCMNV NL8-CA genome encoded a single polyprotein of 3,071 aa. Both TN1a and 1755b genomes were found to be 9,628 nt long, excluding the poly (A), and both genomes encoded a single polyprotein of the same size as NL8CA (3,071 aa). The sequences of all three isolates were compared with the known BCMNV genomes using the BLASTn 2.2.17 tool (Altschul et al. 1997), and the NL8-CA sequence was found to be 99\% identical to the BCMNV-TM70 sequence (GenBank accession number KX302007) and 98\% identical to the BCMNV-NL8 sequence (PG-III; HQ229994). TN1a and 1755b sequences were found to be 99\% identical to the TN1 (PG-VI; HQ229995) and NL3 (PG-VI; AY282577) sequences.

The whole genomes for NL8-CA (PG-III; accession number KY659304), TN1a (PG-VI; KY659306), and 1755b (PG-VI; KY659305), together with NL8 (HQ229994; PG-III), TM70 (KX302007; unknown PG), TN1 (HQ229995; PG-VI), and NL3 (AY282577; PG-VI), were aligned using CLUSTALX, and further analysis was conducted with the RDP4 program package. No recombination was found by the programs from the RDP4 package. The comparison of the seven sequences using the manual distance plot analysis is shown in Supplementary Figure S1A and B, with the fulllength NL3 or NL8 sequences used as references. Relative distance from the reference sequence was calculated using Kimura model (Kimura 1980). Based on the analysis, two areas of the BCMNV genome could be identified as having higher divergence between PG-III and PG-VI sequences: the P1/HC-Pro area, nucleotides 1 to 1,500, and the HC-Pro/P3 area, nucleotides 2,500 to 3,600. When the sequences were analyzed against the PG-VI reference, NL3, an additional potential area of divergence between PG-III and PG-VI sequences, was revealed in the CI cistron, nucleotides 4,500 to 5,100 . However, this region apparently represented a general diversity area between all BCMNV sequences, which was clear when the PG-III reference sequence, NL8, was used for the comparison.

\section{DISCUSSION}

Of the seven alleles governing the resistance to the BCMV$\mathrm{BCMNV}$ complex in common bean, only one, the recessive $b c-3$, was identified as the translation initiation eIF4E factor gene with the known mechanism of resistance expression (Hart and Griffiths 2013; Naderpour et al.2010). The resistance conferred by mutations in the eIF4E factor was found to affect replication of potyviruses

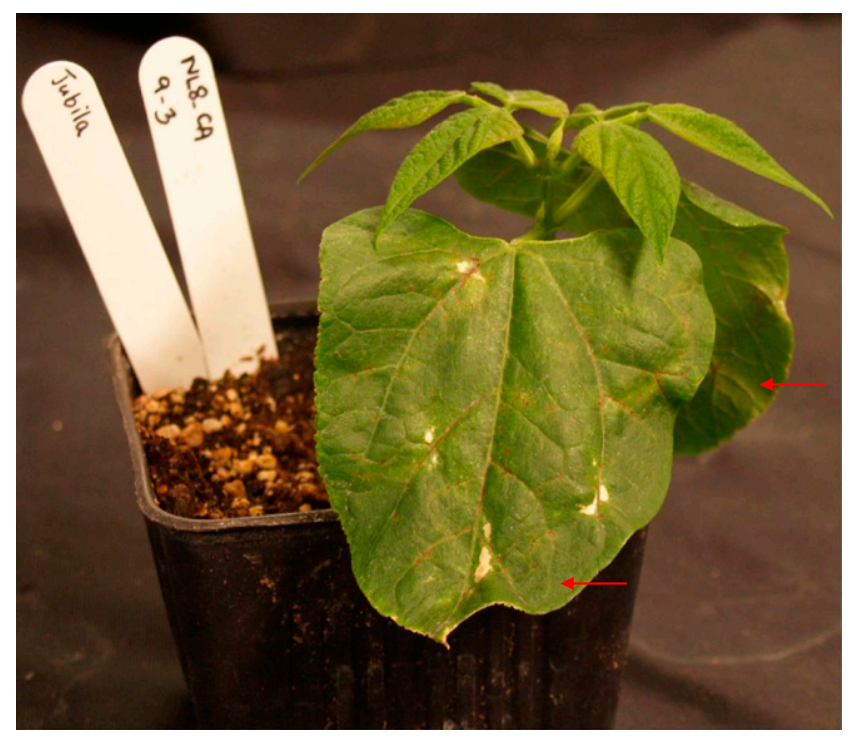

Fig. 2. Symptoms exhibited in Phaseolus vulgaris Jubila $(I, b c-1)$ infected with the NL8-CA isolate of Bean common mosaic necrosis virus, 6 days postinoculation. The two inoculated primary leaves are marked by arrows.

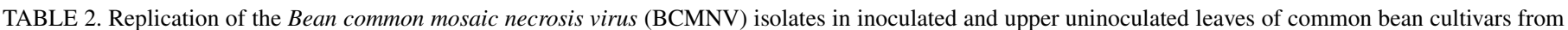

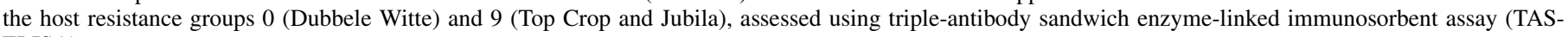
ELISA) $)^{\mathrm{a}}$

\begin{tabular}{|c|c|c|c|c|c|c|}
\hline Cultivar (resistance genotype) & Tested leaf & Time of testing ${ }^{\mathrm{b}}$ & NL8-CA (PG-III) & TN1a (PG-VI) & 1755b (PG-VI) & TN1 (PG-VI), control \\
\hline \multirow[t]{3}{*}{ Top Crop $(I, b c-1)$} & Inoculated $^{\mathrm{c}}$ & 10 dpi & $6 / 6$ & $6 / 6$ & $6 / 6$ & $6 / 6$ \\
\hline & Uninoculated $^{\mathrm{d}}$ & 3 wpi & $0 / 0$ & nt & nt & nt \\
\hline & $\ldots$ & 5 wpi & $0 / 0$ & nt & $\mathrm{nt}$ & nt \\
\hline \multirow[t]{3}{*}{ Jubila $(I, b c-1)$} & Inoculated $^{c}$ & $10 \mathrm{dpi}$ & $6 / 6$ & $6 / 6$ & $6 / 6$ & $6 / 6$ \\
\hline & Uninoculated $^{\mathrm{d}}$ & 3 wpi & $0 / 0$ & $6 / 6$ & $6 / 6$ & $6 / 6$ \\
\hline & $\ldots$ & 5 wpi & $3 / 6^{\mathrm{e}}$ & $6 / 6$ & $6 / 6$ & $6 / 6$ \\
\hline \multirow[t]{2}{*}{ Dubbele Witte (none) } & Inoculated ${ }^{\mathrm{c}}$ & $10 \mathrm{dpi}$ & $2 / 2$ & $2 / 2$ & $2 / 2$ & $2 / 2$ \\
\hline & Uninoculated $^{\mathrm{f}}$ & 5 wpi & $2 / 2$ & $2 / 2$ & $2 / 2$ & $2 / 2$ \\
\hline
\end{tabular}

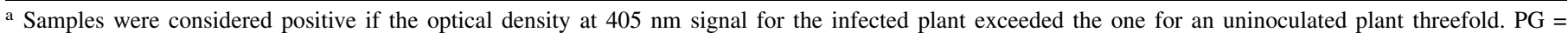
pathogroup and nt designates not tested due to the rapid whole-plant necrosis reaction.

b Abbreviations: dpi = days postinoculation and wpi $=$ weeks postinoculation.

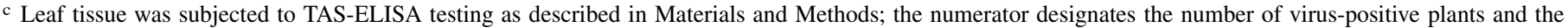
denominator designates the total number of tested plants.

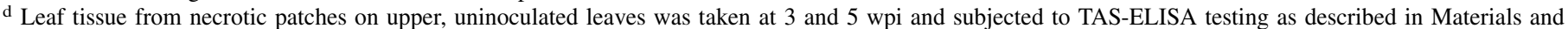
Methods; the numerator designates the number of virus-positive plants and the denominator designates the total number of plants inoculated with the corresponding isolate.

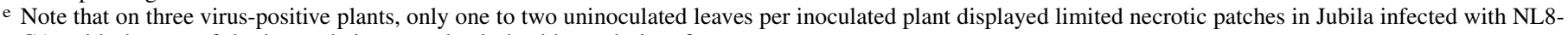
$\mathrm{CA}$, with the rest of the leaves being completely healthy and virus free.

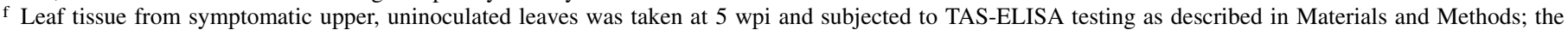
numerator designates the number of virus-positive plants and the denominator designates the total number of plants inoculated with the corresponding isolate. 



Fig. 3. Symptoms exhibited in Phaseolus vulgaris Jubila $(I, b c-1)$ infected with four isolates of Bean common mosaic necrosis virus 10 days postinoculation. Isolates inoculated were A, NL8-CA; B, TN1; C, TN1a; and $\mathbf{D}, 1755 \mathrm{~b}$. The inoculated, primary leaves of infected plants are marked by an arrow and $\mathrm{H}$ marks a healthy plant.
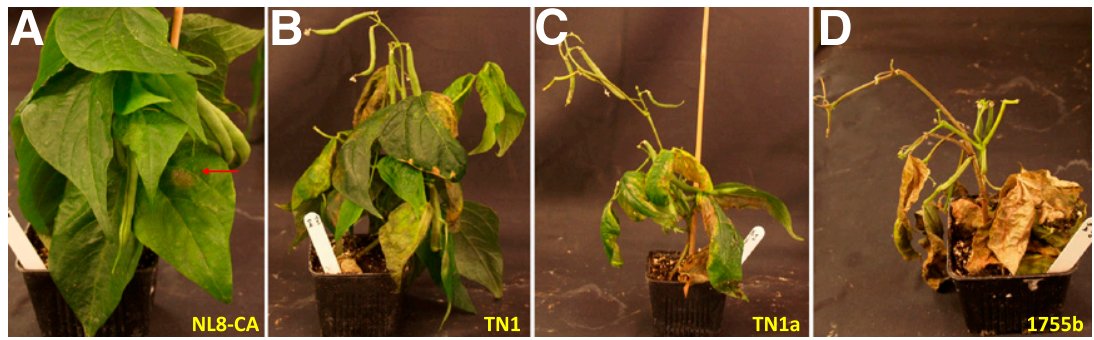

Fig. 4. Systemic symptoms exhibited in Phaseolus vulgaris Jubila $(I, b c-1)$ infected with four isolates of Bean common mosaic necrosis virus 5 weeks postinoculation. Isolates inoculated were A, NL8-CA; B, TN1; C, TN1a; and D, 1755b. Note the limited systemic vein necrosis on an uninoculated leaf of a plant infected with NL8-CA (A), marked by an arrow.

due to disrupted interactions between the eIF4E factor and the VPg protein covalently linked to the $5^{\prime}$ terminus of the Potyvirus genome (Revers and García 2015; Truniger and Aranda 2009). It was also demonstrated that the dominant $I$ gene conferring resistance to a broad range of BCMV and BCMNV isolates in common bean did so due to the induction of the hypersensitive resistance (HR) response, and was unable to affect replication of BCMNV in a single infected cell, exerting the HR during the cell-to-cell movement of the virus (Caddle-Davidson and Jahn 2005; Collmer et al. 2000). Mechanisms of action of the three other resistance genes $(b c-u, b c-1 /$ $b c-1^{2}$, and $\left.b c-2 / b c-2^{2}\right)$ in common bean remained unknown.

The current study of the phenotypic differences between PG-III and PG-VI isolates of BCMNV in common bean cultivars belonging to the host resistance groups 2 (bc- $u$ and $b c-1), 3\left(b c-u\right.$ and $\left.b c-l^{2}\right)$, and 9 (I and $b c-1)$ strongly suggested that the $b c-1$ alleles affect the systemic spread of BCMNV isolates from PG-III in common bean. Indeed, there was no difference in virus spread in inoculated leaves (cell-to-cell movement) of either PG-III (isolate NL8-CA) or PG-VI (isolates TN1, TN1a, and 1755b) BCMNV in both Redlands Greenleaf $C$ and Redlands Greenleaf B, as determined by ELISA data (Fig. 5), and in Top Crop or Jubila, as determined by the local necrotic symptom development (Figs. 1 to 3 ) or by ELISA data (Table 2). Systemic spread of the PG-III and PG-VI isolates, on the other hand, was drastically different, with NL8-CA being unable to move efficiently long distance to the upper, uninoculated leaves of both Top Crop and Jubila (HG-9). The apparent difference between WPN induced by PG-VI isolates in Top Crop (Fig. 1; Table 1), and a milder systemic necrosis induced by the same isolates in Jubila (Fig. 3; Tables 1 and 2), could be interpreted as a slower systemic spread of the PG-VI isolates of BCMNV in the latter host. Hence, the systemic necrotic reaction observed in Top Crop and in Jubila infected with PG-VI isolates of BCMNV would be due to the expression of the $I$ gene following the systemic spread of the virus that could not be confined to inoculated leaves in the presence of the $b c-1$ allele. The proposed role of the $b c-1$ allele in the impairment of the systemic or long-distance movement of BCMNV isolates from PG-III in bean cultivars belonging to HG-9 ( $I$ and $b c-l)$ is consistent with the impairment of the same PG-III isolate systemic movement in HG-2 (bc- $u$ and $b c-1)$ and HG-3 (bc- $u$ and $\left.b c-1^{2}\right)$ cultivars such as Redlands Greenleaf C and Redlands Greenleaf B, respectively (Table 3).

Several single dominant genes, named RTM, were identified in Arabidopsis thaliana restricting systemic movement of Tobacco etch virus (TEV) and conferring resistance against TEV and at least two other unrelated potyviruses (Mahajan et al. 1998). Two dominant, temperature-sensitive resistance genes (Wsml and Wsm2) were found to restrict systemic movement of two potyviruses in wheat (Tatineni et al. 2016). A recessive resistance gene $r a$ was identified in potato, conferring resistance to Potato virus $A$ by blocking vascular transport (Hämäläinen et al. 2000), and another recessive resistance locus, sha3, was identified in A. thaliana, conferring resistance to Plum pox virus through restriction of systemic spread (Pagny et al. 2012). Recently, a recessive eIF4(iso)4E translation initiation factor gene was also suggested to be involved in long-distance movement of TEV in A. thaliana (Contreras-Paredes et al. 2013). Consequently, involvement of the recessive $b c-1$ resistance gene in systemic spread of BCMNV in common bean may be similar to these examples of recessive resistance to potyviruses from $A$. thaliana and potato. 


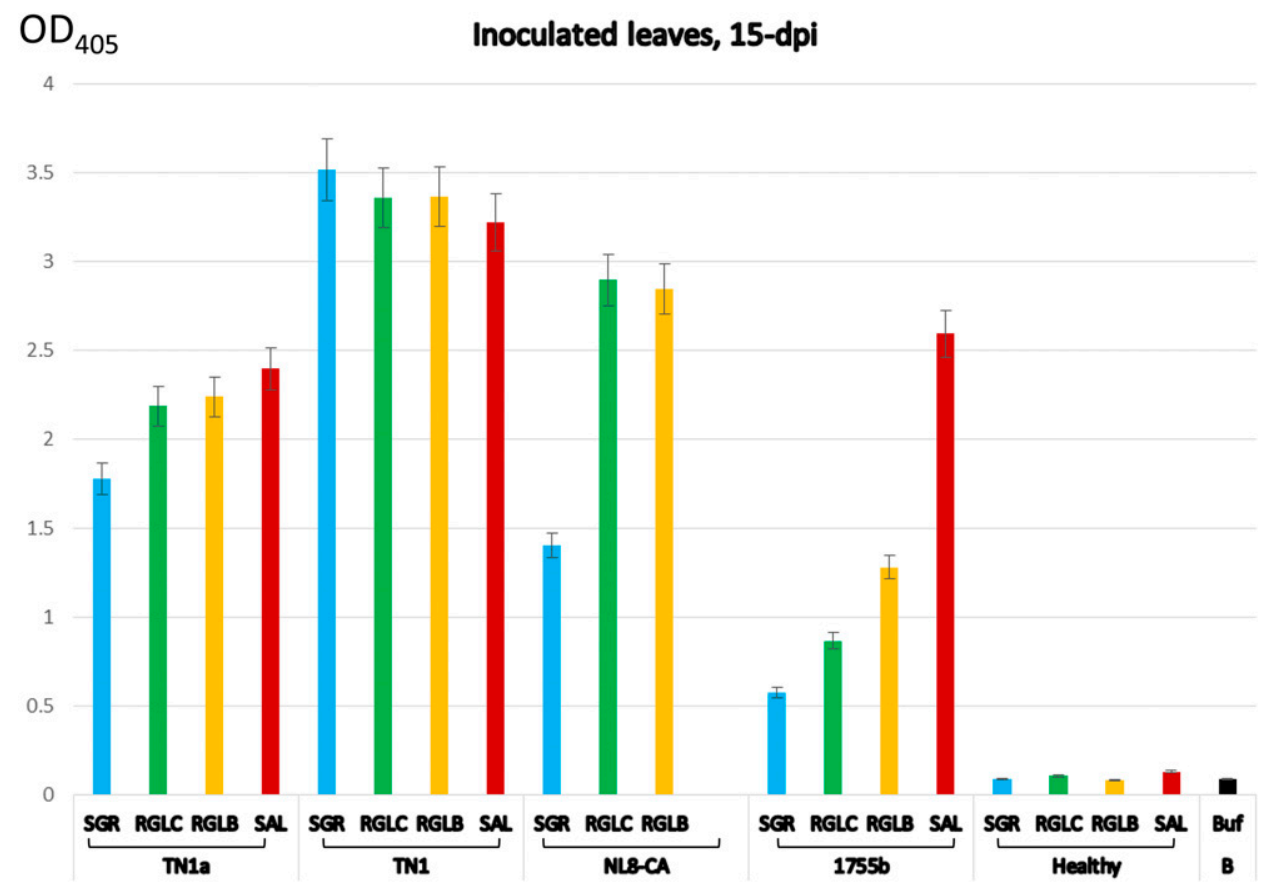

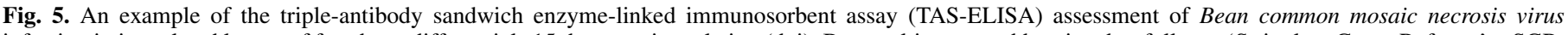

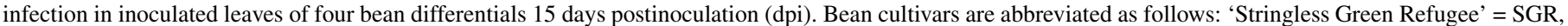

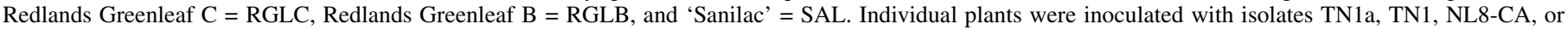

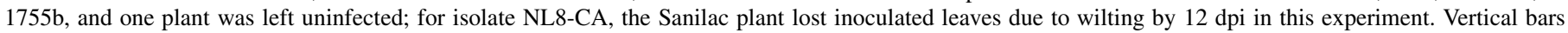


density at $405 \mathrm{~nm}\left(\mathrm{OD}_{405}\right)$ signal for the infected plant exceeded the one for an uninoculated plant threefold.

Previously, three virus cistrons were demonstrated to be involved in systemic spread of potyviruses: capsid protein (CP) (Carbonell et al. 2013; Decroocq et al. 2009; Desbiez et al. 2014; Dolja et al. 1995; Tatineni et al. 2011), VPg (Hämäläinen et al. 2000; Rajamäki and Valkonen 1999, 2002; Schaad et al. 1997), and 6K2 (Rajamäki and Valkonen 1999). No substitutions specific to NL8-like sequences were identified to suggest effects of these BCMNV cistrons on systemic spread of NL8-CA in common bean cultivars expressing $b c-1$ alleles when $6 \mathrm{~K} 2, \mathrm{VPg}$, and $\mathrm{CP}$ of $\mathrm{BCMNV}$ isolates NL8-CA, TN1a, and 1755b were aligned (not shown). Other cistrons in BCMNV have to be involved in restriction of systemic movement of the virus in common bean. Given the high level of identity between PG-III and PG-VI isolates of BCMNV (Larsen et al. 2011), would it be possible to identify genome regions of BCMNV that differ between the two PG and, thus, might be putatively involved in interactions with the $b c-1$ alleles? It appeared that two genomic regions demonstrated divergence between the two $\mathrm{PG}$ of BCMNV rather than between sequences within each PG; these are the P1/HC-Pro area, nucleotides 1 to 1,500, and the HCPro/P3 area, nucleotides 2,500 to 3,600. Nevertheless, their role in defining the PG-III phenotype of BCMNV needs to be tested directly through reverse genetics experimentation.

Because a relatively small proportion of upper, uninoculated leaves in Redlands Greenleaf C and Redlands Greenleaf B became systemically infected with the NL8-CA isolate (Table 3), without any visible symptoms, this should be interpreted as only partial resistance to the NL8 strain of BCMNV (Cooper and Jones 1983). The original identification and characterization of the $b c-1$ and $b c-1^{2}$ alleles occurred in the period preceding the wide use of laboratory techniques for virus testing and typing, and relied primarily on visual symptoms and reinfection of susceptible hosts (Drijfhout 1978). This may explain why this partial resistance nature of the $b c-1$ and $b c-1^{2}$ alleles was not noticed earlier (Strausbaugh et al. 2003b). On a practical level, the fact that BCMNV isolates from PG-III may still systemically infect common bean cultivars expressing $b c-1$ alleles, albeit inefficiently, highlights the value of pyramiding resistance to
TABLE 3. Visual and laboratory assessment of Bean common mosaic necrosis virus (BCMNV) isolate NL8-CA infection in bean cultivars from host resistance groups 2 and $3^{\mathrm{a}}$

\begin{tabular}{|c|c|c|c|c|c|}
\hline \multirow[b]{2}{*}{$\begin{array}{l}\text { Cultivar (resistance } \\
\text { genotype) }\end{array}$} & \multirow[b]{2}{*}{ Plant ID } & \multicolumn{2}{|c|}{$\begin{array}{l}\text { Inoculated leaves, } \\
2 \text { wpi }\end{array}$} & \multicolumn{2}{|c|}{$\begin{array}{l}\text { Uninoculated } \\
\text { leaves, } \\
5 \text { wpi }\end{array}$} \\
\hline & & Symptoms & $\begin{array}{c}\text { ELISA } \\
\text { test }\end{array}$ & Symptoms & $\begin{array}{c}\text { ELISA } \\
\text { test }\end{array}$ \\
\hline Redland Greenleaf & RGLC-1 & NS & $2 / 2$ & NS & $2 / 25$ \\
\hline $\mathrm{C}(b c-u, b c-1)$ & RGLC-2 & NS & $2 / 2$ & NS & $3 / 23$ \\
\hline Redland Greenleaf & RGLB-1 & NS & $2 / 2$ & NS & $1 / 31$ \\
\hline $\mathrm{B}\left(b c-u, b c-1^{2}\right)$ & RGLB-2 & NS & $2 / 2$ & NS & $1 / 42$ \\
\hline
\end{tabular}

${ }^{a}$ Numerator $=$ the number of leaves per plant found BCMNV-positive in triple-antibody sandwich enzyme-linked immunosorbent assay (TASELISA) and denominator $=$ number of leaves per plant tested in TASELISA; wpi = weeks postinoculation and NS = no symptoms.

BCMNV in breeding material with multiple resistance alleles. It also points to the laboratory methods of BCMNV detection in asymptomatic leaves as a necessity when analyzing breeding material for resistance to the virus.

\section{ACKNOWLEDGMENTS}

We thank A. Poplawsky and O. V. Nikolaeva for helpful advice and J. Chojnacky and G. Orellana for laboratory and greenhouse help. This work was funded, in part, through grants from the Idaho Bean Commission, the Idaho State Department of Agriculture, and the USDA National Institute of Food and Agriculture (Hatch project IDA01560); and by the Idaho Agricultural Experiment Station.

\section{LITERATURE CITED}

Adams, M. J., Zerbini, F. M., French, R., Rabenstein, F., Stenger, D. C., and Valkonen, J. P. T. 2012. Family Potyviridae. Pages 1069-1089 in: Virus Taxonomy. Ninth Report of the International Committee on Taxonomy of 
Viruses. A. King, M. Adams, E. Carstens, and E. Lefkowitz, eds. Elsevier, Oxford.

Ali, M. A. 1950. Genetics of resistance to the common bean mosaic virus (bean virus 1) in the bean (Phaseolus vulgaris L.). Phytopathology 40:69-79.

Altschul, S. F., Madden, T. L., Schaffer, A., Zhang, J., Zhang, Z., Miller, W., and Lipman, D. J. 1997. Gapped BLAST and PSI-BLAST: A new generation of protein database search programs. Nucleic Acids Res. 25:3389-3402.

Cadle-Davidson, M. M., and Jahn, M. 2005. Resistance conferred against Bean common mosaic virus by the incompletely dominant $I$ locus of Phaseolus vulgaris is active at the single cell level. Arch. Virol. 150:2601-2608.

Carbonell, A., Maliogka, V. I., Pérez, J. J., Salvador, B., San León, D., García, J. A., and Simón-Mateo, C. 2013. Diverse amino acid changes at specific positions in the N-terminal region of the coat protein allow Plum pox virus to adapt to new hosts. Mol. Plant-Microbe Interact. 26:1211-1224.

Collmer, C. W., Marston, M. F., Taylor, J. C., and Jahn, M. 2000. The I gene of bean: A dosage-dependent allele conferring extreme resistance, hypersensitive resistance, or spreading vascular necrosis in response to the potyvirus Bean common mosaic virus. Mol. Plant-Microbe Interact. 13:1266-1270.

Contreras-Paredes, C. A., Silva-Rosales, L., Daros, J. A., Alejandri-Ramirez, N. D., and Dinkova, T. D. 2013. The absence of eukaryotic initiation factor eIF(iso)4E affects the systemic spread of a Tobacco etch virus isolate in Arabidopsis thaliana. Mol. Plant-Microbe Interact. 26:461-470.

Cooper, J. I., and Jones, A. T. 1983. Responses of plants to viruses: Proposals for the use of terms. Phytopathology 73:127-128.

Decroocq, V., Salvador, B., Sicard, O., Glasa, M., Cosson, P., Svanella-Dumas, L., Revers, F., García, J. A., and Candresse, T. 2009. The determinant of potyvirus ability to overcome the RTM resistance of Arabidopsis thaliana maps to the N-terminal region of the coat protein. Mol. Plant-Microbe Interact. 22:1302-1311.

Desbiez, C., Chandeysson, C., and Lecoq, H. 2014. A short motif in the Nterminal part of the coat protein is a host-specific determinant of systemic infectivity for two potyviruses. Mol. Plant Pathol. 15:217-221.

Dolja, V. V., Haldeman-Cahill, R., Montgomery, A. E., Vandenbosch, K. A., and Carrington, J. C. 1995. Capsid protein determinants involved in cell-to-cell and long distance movement of Tobacco etch potyvirus. Virology 206:1007-1016.

Drijfhout, E. 1978. Genetic Interaction Between Phaseolus vulgaris and Bean common mosaic virus with Implications for Strain Identification and Breeding for Resistance. Centre for Agricultural Publication and Documents, Wageningen, The Netherlands.

Drijfhout, E., and Morales, F. 2005. Bean Common Mosaic. Pages 60-62 in: Compendium of Bean Diseases, 2nd ed. H. F. Schwartz, J. R. Steadman, R. Hall, and R. L. Forster, eds. The American Phytopathological Society, St. Paul, MN.

Fang, G. W., Allison, R. F., Zambolim, E. M., Maxwell, D. P., and Gilbertson, R. L. 1995. The complete nucleotide sequence and genome organization of bean common mosaic virus (NL3 strain). Virus Res. 39:13-23.

Feng, X., Myers, J. R., and Karasev, A. V. 2015. Bean common mosaic virus isolate exhibits a novel pathogenicity profile in common bean, overcoming the $b c-3$ resistance allele coding for the mutated eIF4E translation initiation factor. Phytopathology 105:1487-1495.

Feng, X., Poplawsky, A. R., and Karasev, A. V. 2014a. A recombinant of Bean common mosaic virus induces temperature-insensitive necrosis in an I genebearing line of common bean. Phytopathology 104:1251-1257.

Feng, X., Poplawsky, A. R., Nikolaeva, O. V., Myers, J. R., and Karasev, A. V. 2014b. Recombinants of Bean common mosaic virus (BCMV) and genetic determinants of BCMV involved in overcoming resistance in common beans. Phytopathology 104:786-793.

Flores-Estévez, N., Acosta-Gallegos, J. A., and Silva-Rosales, L. 2003. Bean common mosaic virus and Bean common mosaic necrosis virus in Mexico. Plant Dis. 87:21-25.

Hämäläinen, J. H., Kekarainen, T., Gebhardt, C., Watanabe, K. N., and Valkonen, J. P. T. 2000. Recessive and dominant genes interfere with the vascular transport of potato virus A in diploid potatoes. Mol. Plant-Microbe Interact. 13:402-412.

Hart, J. P., and Griffiths, P. D. 2013. A series of $e I F 4 E$ alleles at the $B c-3$ locus are associated with recessive resistance to Clover yellow vein virus in common bean. Theor. Appl. Genet. 126:2849-2863.

Kimura, M. 1980. A simple method for estimating evolutionary rates of base substitutions through comparative studies of nucleotide sequences. J. Mol. Evol. 16:111-120.
Larsen, R. C., Druffel, K. L., and Wyatt, S. D. 2011. The complete nucleotide sequences of bean common mosaic necrosis virus strains NL-5, NL-8 and TN-1. Arch. Virol. 156:729-732.

Larsen, R. C., Miklas, P. N., Druffel, K. L., and Wyatt, S. D. 2005. NL-3 K Strain is a stable and naturally occurring interspecific recombinant derived from Bean common mosaic necrosis virus and Bean common mosaic virus. Phytopathology 95:1037-1042.

Mahajan, S. K., Chisholm, S. T., Whitham, S. A., and Carrington, J. C. 1998. Identification and characterization of a locus (RTM1) that restricts longdistance movement of tobacco etch virus in Arabidopsis thaliana. Plant J. 14:177-186.

Maina, S., Edwards, O. R., de Almeida, L., Ximenes, A., and Jones, R. A. C. 2016. First complete genome sequence of Bean common mosaic necrosis virus from East Timor. Genome Announc. 4:e01049-16.

Martin, D. P., Williamson, C., and Posada, D. 2005. RDP2: Recombination detection and analysis from sequence alignments. Bioinformatics 21: 260-262.

Mink, G. I., and Silbernagel, M. J. 1992. Serological and biological relationships among viruses in the bean common mosaic virus subgroup. Arch. Virol. Suppl. 5:397-406.

Morales, F. J., and Bos, L. 1988. Bean common mosaic virus. Online publication. Descriptions of Plant Viruses No. 337. http://www.dpvweb.net/dpv/ showdpv.php?dpvno=337

Naderpour, M., Lund, O. S., Larsen, R., and Johansen, E. 2010. Potyviral resistance derived from cultivars of Phaseolus vulgaris carrying $b c-3$ is associated with the homozygotic presence of a mutated $e I F 4 E$ allele. Mol. Plant Pathol. 11:255-263.

Pagny, G., Paulstephenraj, P. S., Poque, S., Sicard, O., Cosson, P., Eyquard, J. P., Caballero, M., Chague, A., Gourdon, G., Negrel, L., Candresse, T., Mariette, S., and Decroocq, V. 2012. Family-based linkage and association mapping reveals novel genes affecting Plum pox virus infection in Arabidopsis thaliana. New Phytol. 196:873-886.

Rajamäki, M. L., and Valkonen, J. P. T. 1999. The 6K2 protein and the VPg of potato virus A are determinants of systemic infection in Nicandra physaloides. Mol. Plant-Microbe Interact. 12:1074-1081.

Rajamäki, M. L., and Valkonen, J. P. T. 2002. Viral genome-linked protein (VPg) controls accumulation and phloem-loading of a potyvirus in inoculated potato leaves. Mol. Plant-Microbe Interact. 15:138-149.

Revers, F., and García, J. A. 2015. Molecular biology of potyviruses. Adv. Virus Res. 92:101-199.

Schaad, M. C., Lellis, A. D., and Carrington, J. C. 1997. VPg of tobacco etch potyvirus is a host genotype-specific determinant for long-distance movement. J. Virol. 71:8624-8631.

Singh, S., and Schwartz, H. F. 2010. Breeding common bean for resistance to diseases: A review. Crop Sci. 50:2199-2223.

Strausbaugh, C. A., Miklas, P. N., Singh, S. P., Myers, J. R., and Forster, R. L. 2003a. Genetic characterization of differential reactions among host group 3 common bean cultivars to NL-3 K strain of Bean common mosaic necrosis virus. Phytopathology 93:683-690.

Strausbaugh, C. A., Myers, J. R., Forster, R. L., and McClean, P. E. 2003b. A quantitative method to screen common bean plants for resistance to Bean common mosaic necrosis virus. Phytopathology 93:1430-1436.

Tatineni, S., Van Winkle, D. H., and French, R. 2011. The N-terminal region of Wheat streak mosaic virus coat protein is a host- and strain-specific longdistance transport factor. J. Virol. 85:1718-1731.

Tatineni, S., Wosula, E. N., Bartels, M., Hein, G. L., and Graybosch, R. A. 2016. Temperature-dependent Wsm1 and Wsm2 gene-specific blockage of viral long-distance transport provides resistance to Wheat streak mosaic virus and Triticum mosaic virus in wheat. Mol. Plant-Microbe Interact. 29: 724-738.

Truniger, V., and Aranda, M. A. 2009. Recessive resistance to plant viruses. Adv. Virus Res. 75:119-159, 231.

Vetten, H. J., Lesemann, D. E., and Maiss, E. 1992. Serotype A and B strains of bean common mosaic virus are two distinct potyviruses. Arch. Virol. Suppl. 5:415-431.

Worrall, E. A., Wamonje, F. O., Mukeshimana, G., Harvey, J. J., Carr, J. P., and Mitter, N. 2015. Bean common mosaic virus and Bean common mosaic necrosis virus: Relationships, biology, and prospects for control. Adv. Virus Res. 93:1-46. 